\title{
Paving the Way for Dose Banding of Chemotherapy: An Analytical Approach
}

\author{
Heike Reinhardt"a Rainer Trittler, PhD ${ }^{\mathrm{b}}$; Alison G. Eggleton, MEd, MSc ${ }^{c}$; Stefan Wöhrl ${ }^{\mathrm{b}}$; \\ Thomas Epting, PhDi; Marion Buck ${ }^{\mathrm{e}}$; Sabine Kaiser ${ }^{\mathrm{e}}$; Daniel Jonas, Prof ${ }^{\mathrm{e}}$; Justus Duyster, Prof ${ }^{\mathrm{a}, \mathrm{f}}$; \\ Manfred Jung, Prof ${ }^{g, h}$; Martin J. Hug, $\mathrm{PhD}^{\mathrm{b}}$; and Monika Engelhardt, Prof ${ }^{\mathrm{a}}$
}

\begin{abstract}
Background: In an interdepartmental cooperation, we investigated the feasibility and benefits of implementing dose banding of chemotherapy at our medical center. Based on this concept, chemotherapy doses are clustered into bands of similar dosage levels, thereby allowing the preproduction of frequently used standard doses of drugs, with sufficient physicochemical stability. Although established practice in the United Kingdom, there is little published evidence of its introduction elsewhere. Methods: We performed an analysis of local prescribing practice (22,310 chemotherapies) and identified gemcitabine, 5-fluorouracil, and carboplatin, among various others, as cytotoxic drugs suitable for dose banding. Results: First, we determined the physicochemical stability of the selected chemotherapy drugs during 12-weeks' storage by performing $\mathrm{pH}$ analysis and visual examination for color change or particles. No relevant changes were identified. Gemcitabine was selected for quantitative high-performance liquid chromatography analysis and we were able to show that $\geq 95 \%$ remained after 12 weeks' storage, in accordance with international guidelines. To simulate a worst case scenario, we performed microbiological stability testing of simulated cytotoxic compounding by replacing the cytotoxic drug with liquid media. Samples were incubated over defined storage time points (3, 6, and 12 weeks) and evaluated using the direct inoculation method. For the container integrity test, we deposited the samples into highly contaminated broth for 1 hour. Microbiological stability was demonstrated in both tests for the full storage period. Conclusions: Our data show that 12-weeks' storage of selected cytotoxic products is feasible from a microbiological perspective. Sterility of prepared products was maintained under extreme storage conditions. Gemcitabine content was in accordance with international guidelines after 12-weeks' storage. These results support the introduction of dose-banded gemcitabine products with the predicted advantages of optimized pharmacy workflow and reduced patient waiting times. We highlight the need for further research and consensus on the performance of purity analyses in dose-banded drug products.
\end{abstract}

J Natl Compr Canc Netw 2017;15(4):484-493

\section{Background}

The number of new cancer cases is increasing (in Germany, 2012: 477,950; 2016: $\approx 500,000$ new cases expected), accompanied by growing demand for treatment. ${ }^{1}$ The associated workload constitutes a major challenge for

From aUniversity Medical Center Freiburg, Department of Hematology and Oncology, Freiburg, Germany; ' University Medical Center Freiburg, Pharmacy, Freiburg, Germany; 'Addenbrooke's Hospital, Cambridge University Hospitals NHS Foundation Trust, Pharmacy Department, Cambridge, United Kingdom; dUniversity Medical Center Freiburg, Department of Clinical Chemistry, Freiburg, Germany; ${ }^{\text {University Medical }}$ Center Freiburg, Environmental Health Sciences and Hospital Infection

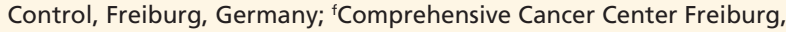
Freiburg, Germany; ${ }^{9}$ Albert-Ludwigs-University Freiburg, Institute of Pharmaceutical Sciences, Freiburg, Germany; and h'German Cancer Consortium (DKTK), Freiburg, Germany.

Submitted November 15, 2016; accepted for publication December 12, 2016. healthcare professionals, with an increased demand for sterile production of chemotherapy drugs within existing workforce constraints. Resulting financial implications are also considerable. For the National Health Service (NHS) in England, for example, chemotherapy is the

The authors have disclosed that they have no financial interests, arrangements, affiliations, or commercial interests with the manufacturers of any products discussed in this article or their competitors.

Author contributions: Study design: Reinhardt, Trittler, Jonas, Epting, Kaiser, Duyster, Jung, Hug, Engelhardt. Data acquisition: Reinhardt, Trittler, Wöhrl, Epting, Buck. Data analysis: Reinhardt, Trittler, Eggleton, Wöhrl, Epting, Buck, Engelhardt. Data interpretation and critical contributions to manuscript: All authors. Drafting of manuscript: Reinhardt, Eggleton, Engelhardt.

Correspondence: Heike Reinhardt, University Medical Center, Department of Hematology, Oncology \& Stem Cell Transplantation, Hugstetterstr. 55, 79106 Freiburg, Germany. E-Mail: heike.reinhardt@uniklinik-freiburg.de 
single biggest spend within the Specialised Commissioning service, costing an estimated $£ 1.4$ billion a year. $^{2}$

In the context of these demands, the concept of dose banding was developed in the United Kingdom in the late 1990s and has since become established clinical practice. ${ }^{3}$ Dosage of intravenous cytotoxic drugs is traditionally calculated on an individual patient basis according to body weight or body surface area (BSA). With dose banding, doses within a defined range, usually $\pm 5 \%$ of the calculated dose, are rounded to an agreed standard midpoint dose. ${ }^{4}$ This approach allows the preproduction of frequently used doses of selected chemotherapy drugs, assuming drug stability and storage conditions are met. Advantages include reduced patient wait times, optimized pharmacy production capacity, quality control within a standardized production process, and potential cost savings. ${ }^{4,5}$ Dose banding is considered a safe practice, with clinical outcomes comparable to those of conventional chemotherapy dosing. , $^{2,-8}$

NHS England has recently introduced a national target of at least $90 \%$ of intravenous chemotherapy doses prescribed using dose banding by March 2018 . The goals are to allow patients to receive treatment closer to home, thus improving their quality of life, and to generate substantial cost savings. ${ }^{2}$ In the United Kingdom, only a few hospital pharmacies hold a manufacturing license, so many production units obtain dose-banded products from commercial suppliers. ${ }^{89}$ For in-house preparation and storage of dose-banded chemotherapy products, a detailed analysis to ensure safety and efficacy of these drug products is imperative. The transferability of published data on extended stability is limited, because pharmaceutical auxiliaries may vary between different brands. Packaging material, local manufacturing processes, and other factors may also influence storage viability. ${ }^{8}$

The primary objectives of the study were:

- To identify the dose-banded chemotherapy products most likely to have an impact on the sterile production service.

- To determine whether the identified drug products are stable from a microbiological and physicochemical perspective for a defined period.

- To perform detailed physicochemical stability analysis on one selected chemotherapy drug product.

\section{Methods}

\section{Ordering Frequency and Prescribing Practice}

A detailed retrospective analysis of 22,310 parenteral chemotherapy products prescribed within the hematology and oncology department at our University Medical Center in 2012 was conducted using the database of our hospital's chemotherapy production software Zenzy (Dr. Heni Software GmbH \& Co. KG, Kirchzarten, Germany). Overall prescribing frequency was assessed (inpatient and outpatient use) and the proportion of doses administered in the outpatient setting was calculated (Table 1). Drugs were tabulated in decreasing order of prescribing frequency. Chemotherapy doses were banded using the logarithmic method described by Zavery and Marsh $^{7}$ (see supplemental eFigure 1, available with this article at JNCCN.org). In the logarithmic dosing scale, $100 \mathrm{mg}$ is used as a starting point, with defined increments of $10.6 \%$ between standard doses going down and $11.8 \%$ going up the scale. ${ }^{7}$ Because this scale can be extended to cover any dose range, it supports the application of one standard banding approach for any chemotherapy drug or antibody. All conventionally calculated doses, irrespective of the dosing method (BSA, body weight, or area under the curve [AUC] for carboplatin), were subsequently banded using one universal scale. The frequency

\begin{tabular}{|c|c|c|}
\hline $\begin{array}{l}\text { Chemotherapy } \\
\text { Product }\end{array}$ & $\begin{array}{c}\text { Number of } \\
\text { Prescribed Doses (\%) } \\
\text { Inpatient + } \\
\text { Outpatient Data } \\
(100 \%)\end{array}$ & $\begin{array}{c}\text { Number of } \\
\text { Prescribed Doses (\%) } \\
\text { Outpatient Data } \\
\text { (59.3\% From Total) }\end{array}$ \\
\hline $\begin{array}{l}\text { Total number } \\
\text { of prescribed } \\
\text { chemotherapy } \\
\text { doses }(\%)\end{array}$ & $22,310(100)$ & $13,237(100)$ \\
\hline Etoposide & $2,031(9.1)$ & $533(4.0)$ \\
\hline Cytarabine & $1,604(7.2)$ & $37(0.3)$ \\
\hline Gemcitabine & $1,532(6.9)$ & $1,338(10.1)$ \\
\hline Rituximab & $1,187(5.3)$ & $798(6.0)$ \\
\hline 5-Fluorouracil bolus & $1,056(4.7)$ & $1,013(7.7)$ \\
\hline Cyclophosphamide & $1,010(4.5)$ & $457(3.5)$ \\
\hline Irinotecan & $854(3.8)$ & $811(6.1)$ \\
\hline Carboplatin & $829(3.7)$ & $546(4.1)$ \\
\hline Cisplatin & $786(3.5)$ & $262(2.0)$ \\
\hline Doxorubicin & 752 (3.4) & $331(2.5)$ \\
\hline
\end{tabular}


of the banded doses of the chemotherapy drugs is shown in Figure 1.

In order to identify the dose-banded products most likely to impact the aseptic production service, the drugs were compared within the dose-banding model. A cutoff (viability limit) was defined for each drug product, indicating the minimum number of prescriptions required per dose band per year to make dose banding worthwhile. Considering the practicability of batch production, the minimum number of prescriptions per dose band and pharmacy production cycle was taken as $5 .^{8}$ The number of production cycles required per year was determined

A

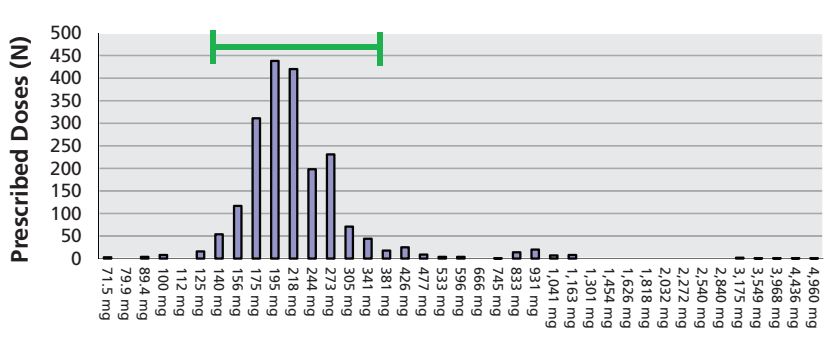

Dose Bands With Respective Midpoint Dose from published stability data by dividing 52 by the stability in weeks of the respective drug. ${ }^{10,11}$ Using gemcitabine as an example, assuming a stability of 12 weeks, ${ }^{11} 5$ production cycles would be required per annum ( 52 weeks/year divided by 12 weeks stability $=5$ cycles $)$ (Table 2$)$. The viability limit for the individual products was obtained by multiplying the number of production cycles per year by 5 (defined minimum number of prescriptions per dose band and production cycle). For gemcitabine, the viability limit will then be 5 production cycles $\mathrm{x} 5$ prescriptions per dose band $=25$ (Table 2, Figure $1 \mathrm{C)}$.
B

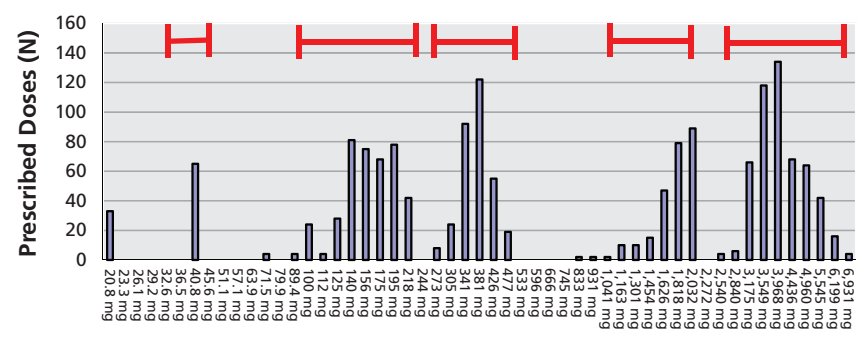

Dose Bands With Respective Midpoint Dose

C

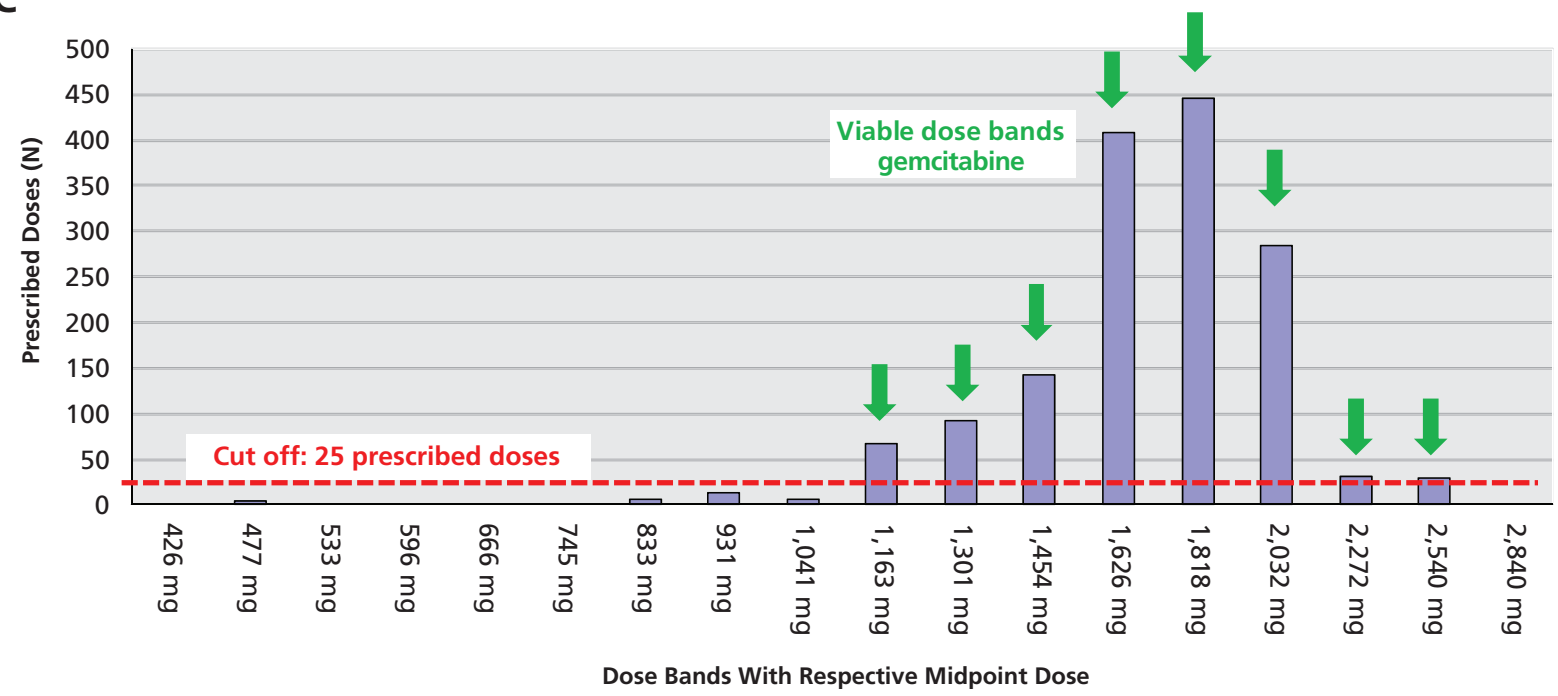

Figure 1. Prescribing pattern of frequently used chemotherapy products. Histograms of all (A) etoposide, (B) cytarabine, and (C) gemcitabine doses prescribed in 2012 clustered to dose bands using the dose-banding model described by Zavery and Marsh. ${ }^{7}$ The height of the columns corresponds to the prescribing frequency of the individual dose band. For etoposide (A) and cytarabine (B), the dose bands with high prescribing frequency are marked by the green or red bars on top. The dashed cutoff line (C) indicates the viability limit of 25 prescribed doses. The 8 viable gemcitabine dose bands exceeding the viability limit are indicated by the green arrows.

x-axis: standard doses; $y$-axis: number of doses prescribed in 2012.

Production cycle: shelf life in weeks (from literature).

Viable dose-band: at least 5 manufactured products per dose band and production cycle.

Number of production cycles/year: 52/stability (wk)

Viability limit: Number of production cycles/y x 5 . 
An Analytical Approach to Dose Banding

\begin{tabular}{|c|c|c|c|c|c|c|c|}
\hline $\begin{array}{l}\text { Manufactured } \\
\text { Drug Product }^{\mathrm{a}}\end{array}$ & $\begin{array}{l}\text { Number of } \\
\text { Prescriptions }\end{array}$ & $\begin{array}{l}\text { Stability } \\
(\mathbf{w k})^{10,11}\end{array}$ & $\begin{array}{c}\text { Production } \\
\text { Cycles/y }\end{array}$ & $\begin{array}{l}\text { Viability Limitc } \\
\text { (Minimum } \\
\text { Number of } \\
\text { Prescriptions } \\
\text { Required } \\
\text { Per Year and } \\
\text { Dose Band) }\end{array}$ & $\begin{array}{c}\text { Number of } \\
\text { Viable Dose } \\
\text { Bands }^{d}\end{array}$ & $\begin{array}{c}\text { Number of } \\
\text { Prescriptions } \\
\text { in Viable Dose } \\
\text { Bands (\%) }\end{array}$ & $\begin{array}{c}\text { Number of } \\
\text { Products Per } \\
\text { Production } \\
\text { Cycle }\end{array}$ \\
\hline Gemcitabine & 1,532 & 12 & 5 & 25 & 8 & $1,503(98 \%)$ & 300 \\
\hline Vincristine & 454 & 4 & 13 & 65 & 2 & $440(97 \%)$ & 34 \\
\hline Doxorubicin & 752 & 17 & 3 & 15 & 15 & $723(96 \%)$ & 241 \\
\hline $\begin{array}{l}\text { Rituximab } \\
\text { (without } \\
\text { intrathecal) }\end{array}$ & 1,186 & 12 & 5 & 25 & 6 & $1,129(95 \%)$ & 225 \\
\hline Irinotecan & 854 & 12 & 5 & 25 & 7 & $808(95 \%)$ & 161 \\
\hline $\begin{array}{l}\text { 5-Fluorouracil } \\
\text { bolus }\end{array}$ & 1,056 & 4 & 13 & 65 & 6 & $972(92 \%)$ & 75 \\
\hline $\begin{array}{l}\text { 5-Fluorouracil } \\
\text { 48-h Baxter } \\
\text { pump }\end{array}$ & 566 & 16 & 4 & 20 & 7 & $502(89 \%)$ & 126 \\
\hline Etoposide & 2,031 & 4 & 13 & 65 & 7 & $1,786(88 \%)$ & 137 \\
\hline Fludarabine & 446 & 5 & 10 & 50 & 4 & $391(88 \%)$ & 39 \\
\hline Bortezomib & 645 & 5 & 10 & 50 & 3 & $513(80 \%)$ & 51 \\
\hline
\end{tabular}

aManufactured products are listed in descending order of viability for dose banding (indicated by \% of prescriptions in viable dose bands). Only substances with $\geq 80 \%$ of prescriptions in viable dose bands are shown.

${ }^{b}$ Number of production cycles per year: 52/stability (wk).

Viability limit: (number of production cycles/y) x 5 (minimum number of prescriptions per dose band and production cycle).

${ }^{d}$ Viable dose band: minimum number of 5 prescriptions per dose band and production cycle (production cycle $=$ shelf life in weeks [from literature]).

\section{Microbiological Stability}

Samples for the microbiological stability analysis were obtained by precisely simulating each step of the cytotoxic compounding process in the pharmacy aseptic production unit using 2 different liquid media to replace the original cytotoxic substance and diluent (Figure 2). Gemcitabine was used as a model for an infusion bag, and 5-fluorouracil for a syringetype product. For each of the 3 defined storage time points (3, 6, and 12 weeks), 2 samples per liquid medium (thioglycollate and tryptone soya) were prepared with 3 samples each for time point 0 , resulting in 18 samples each of the infusion bags and syringes. An intravenous administration set was attached to each infusion bag and filled with diluent (liquid medium) replicating the normal production process. Samples were stored at $28^{\circ} \mathrm{C}$ for a maximum of 3 months. Sterility testing was performed immediately after the sterile production process and after 3,6 , and 12 weeks. The direct inoculation method, described in the European Pharmacopoeia (Ph. Eur.) was validated and used for evaluation of sterility (Figure 2).12 After the maximum storage time, a container in- tegrity test was performed on 3 of the tryptone soya sample infusion bags and syringes. ${ }^{13}$ These sample products were placed into Mueller-Hinton broth contaminated with $10^{6} \mathrm{CFU} / \mathrm{mL}$ Escherichia coli $\mathrm{J} 53$ for 1 hour. After removal, the compounded products were incubated at $20^{\circ} \mathrm{C}$ to $25^{\circ} \mathrm{C}$ (in accordance with the $\mathrm{Ph}$. Eur. standard for incubation of tryptone soya broth) for 14 days and examined for microbiological growth by direct inoculation.

\section{Physical and Chemical Stability}

Sample Preparation and Sampling Times: For 2 cytotoxic agents given by intravenous infusion, gemcitabine and carboplatin, 18 infusions ( 9 with and 9 without an intravenous administration set attached) were prepared at concentrations equivalent to 3 standard doses based on the analysis of prescribing practice. For example, for gemcitabine, the standard doses selected were the lowest $(1,163 \mathrm{mg})$, highest $(2,540 \mathrm{mg})$, and most frequently prescribed $(1,818$ $\mathrm{mg}$ ) viable dose bands, resulting in infusion concentrations of $4 \mathrm{mg} / \mathrm{mL}, 8 \mathrm{mg} / \mathrm{mL}$, and $5.95 \mathrm{mg} / \mathrm{mL}$, respectively (Figure $1 \mathrm{C}$ ). Three sample syringes of 


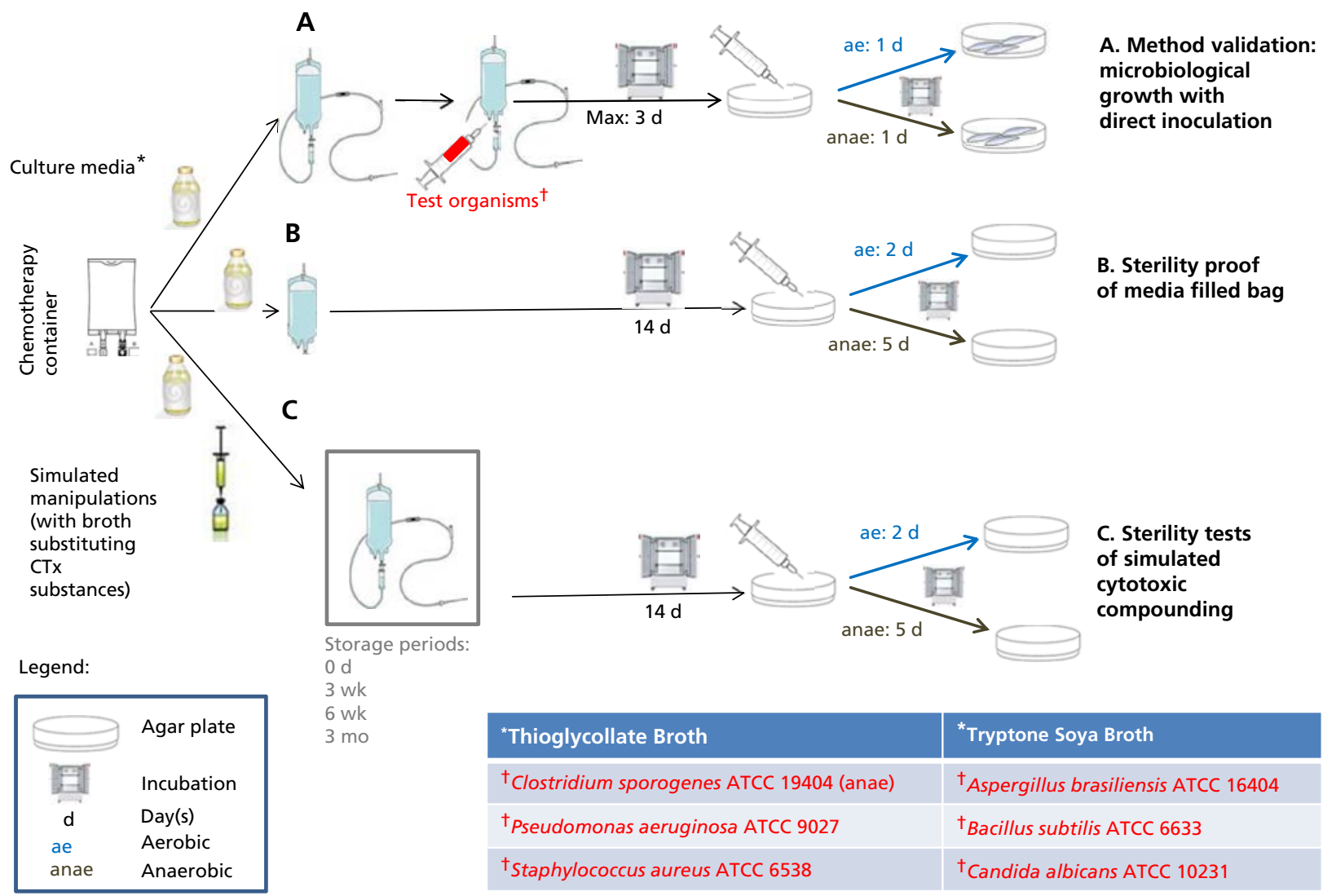

Figure 2. Microbiological testing for prolonged sterility by applying the direct inoculation method. (A) A method validation was performed by using liquid media and the test organisms described in the European Pharmacopoeia. ${ }^{12}$ (B) Through incubation of the media-filled chemotherapy bags, initial sterility is shown. In the actual sterility test, the preparation of cytotoxic drugs was simulated step-by-step using liquid medium instead of cytotoxic drugs. (C) The resulting products were stored for different storage times up to 12 weeks and then tested for sterility. Abbreviations: ae, aerobic; anae, anaerobic; CTx, chemotherapy; max, maximum.

undiluted 5-fluorouracil were prepared because further dilution of the manufacturer's product is not required.

The cytotoxic products were stored just above normal room temperature $\left(26^{\circ} \mathrm{C}\right)$ for 3 months. This temperature was selected to cover for potential temperature deviations during the summer months. During the 3 months' storage, samples were visually inspected for change of color and the presence of particles against black and white backgrounds in accordance with the method defined in the Ph. Eur. at weeks $0,1.5,3,6,9$, and 12 . The $\mathrm{pH}$ value was determined at weeks 0 and 12 (Table 3 ).

Gemcitabine was selected as the initial agent for high-pressure liquid chromatography (HPLC) purity and quantitative assay. Samples for the HPLC analysis were withdrawn through the injection port of the gemcitabine bags at weeks $0,1.5,3,6,9$, and 12 .
Purity Analysis: HPLC analysis (Elite LaChrom, VWR-Hitachi, Tokyo, Japan) was performed using a C18 column (CC 125/4 Nucleodur 100-5 C 18 ec, Macherey-Nagel, Düren, Germany), L-2420 UV-Vis Detector (Elite LaChrom, VWR-Hitachi, Tokyo, Japan), L-2200 Autosampler (Elite LaChrom, VWRHitachi, Tokyo, Japan), and L-2130 HPLC Pump (Elite LaChrom, VWR-Hitachi, Tokyo, Japan). The mobile phase consisted of $1 \mathrm{~mL}$ of phosphoric acid $85 \%$ made up to $1 \mathrm{~L}$ with distilled water and $30 \mathrm{~mL}$ methanol $\mathrm{R}$ added thereafter. An isocratic method was used with a flow rate of $1 \mathrm{~mL} / \mathrm{min}$ and injection volume of $1 \mathrm{mcL}$. The analysis was conducted at different wavelengths: $275 \mathrm{~nm}$ (from Ph. Eur. ${ }^{12}$ ), 238 $\mathrm{nm}$ (as for the quantitative analysis of gemcitabine), and $210 \mathrm{~nm}$ (adapted from Jansen et $\mathrm{a}^{14}$ ). A literature search was conducted using PubMed, Reaxys, and SciFinder to identify predicted impurities and 
An Analytical Approach to Dose Banding

\begin{tabular}{|c|c|c|c|c|}
\hline Type of Investigation & Times of Investigation & Gemcitabine Infusion Bags & 5-Fluorouracil Syringes & Carboplatin Infusion Bags \\
\hline $\mathrm{pH}$ changes & Weeks 0 and 12 & $<0.1$ & $<0.05$ & $\leq 0.21$ \\
\hline Color & Weeks $0,1.5,3,6,9$, and 12 & Colorless, no change in color & $\begin{array}{l}\text { Opalescent, no change in } \\
\text { color }\end{array}$ & Colorless, no change in color \\
\hline Particles & Weeks $0,1.5,3,6,9$, and 12 & No particles & No particles & Few floating particles ${ }^{a}$ \\
\hline
\end{tabular}

Defined acceptance criteria: $\mathrm{pH}$ changes: $\leq \pm 0.3$ from initial $\mathrm{pH}$; color: no changes in color accepted; particles: none accepted (except justified individual cases, provided strict measures are implemented and officially communicated).

${ }^{a}$ Announcement of the Federal Institute for Drugs and Medical Devices (BfArM) from October 7, 2012: recommendation to filter certain carboplatin-containing drugs with a $0.2 \mathrm{mcm}$ filter. ${ }^{18}$

their properties. Impurities present in the samples were identified via ultraviolet (UV) and mass spectrometry and subsequent comparison with the literature..$^{12,14}$

The quantification of impurities was performed using the chromatograms obtained at $275 \mathrm{~nm}$ and comparison with the gemcitabine AUC in accordance with the gemcitabine $\mathrm{Ph}$. Eur. monograph. ${ }^{12}$

Quantitative Analysis: The HPLC quantitative assay was performed the same as for the purity analysis, with detection at $238 \mathrm{~nm}$, to identify the quantity of gemcitabine present in the solution at different storage time points. The method applied complied with the suitability criteria described in the Ph. Eur. ${ }^{12}$ The initial gemcitabine content (determined at week 0) was set as $100 \%$. The change in gemcitabine content over time was then compared with international guidance. ${ }^{15-17}$

\section{Results}

\section{Ordering Frequency and Prescribing Practice}

From 22,310 (100\%) parenteral chemotherapy products prescribed during 2012, the most frequently ordered cytotoxic drugs overall were etoposide $(2,031$; $9.1 \%)$, cytarabine $(1,604 ; 7.2 \%)$, and gemcitabine $(1,532 ; 6.9 \%)$ (Table 1$)$. In the outpatient clinic, 13,237 (59.3\% of the total) chemotherapy products were prescribed. Of these, gemcitabine $(1,338$; $10.1 \%)$ and 5 -fluorouracil bolus $(1,013 ; 7.7 \%)$ were most frequently ordered (Table 1 ).

A comparison of chemotherapy drugs with regard to viability of dose banding is shown in Table 2. Gemcitabine was suitable for dose banding as $98 \%(1,503)$ of the total gemcitabine prescriptions $(1,532)$ fell into viable dose bands (Table 2$)$. The 8 viable dose bands identified for gemcitabine are shown in Figure 1C. Other potentially suitable drugs were rituximab (95\%), 5-fluorouracil bolus (92\%), and etoposide (88\%) (Table 2, Figure 1A). Cytarabine was unsuitable for dose banding due to a widely scattered range of dose bands of variable frequency, risking wasted pharmacy effort (Figure 1B). Based on these results and a consideration of practical aspects, gemcitabine and carboplatin infusions and 5-fluorouracil bolus were selected for further investigation of stability.

\section{Microbiological Stability}

Sterility testing of all infusion and bolus samples showed no microbiological contamination at weeks $0,3,6$, or 12 (Figure 2C). The container integrity test showed similar results. After insertion of the media-filled syringes and infusion bags with intravenous administration sets into the contaminated broth, all remained sterile.

\section{Physical and Chemical Stability}

Visual Inspection and pH Analysis: Results of the visual inspection are shown in Table 3. The finding of the very few floating particles detected in the carboplatin bags is a known phenomenon (Table 3). ${ }^{18}$ Results of the $\mathrm{pH}$ analysis showed minimal deviation between weeks 0 and 12 for the gemcitabine $(<0.1)$ and fluorouracil $(<0.05)$ samples. For carboplatin, $\mathrm{pH}$ deviation over storage time was $<0.1$ (12 samples) or $<0.2$ ( 5 samples), with a maximum deviation of 0.21 (1 sample) (Table 3).

Purity Analysis: The gemcitabine purity analysis revealed a varying number of impurity peaks in the chromatogram depending on the wavelength used for detection. Using the detection wavelength of $275 \mathrm{~nm}$ (Ph. Eur.), one impurity was eluted at a retention time of 12.8 minutes (Figure 3A). The same impurity was noted at 12.8 minutes in the chromatogram obtained at $238 \mathrm{~nm}$, but with a higher AUC (Figure 
Reinhardt et al

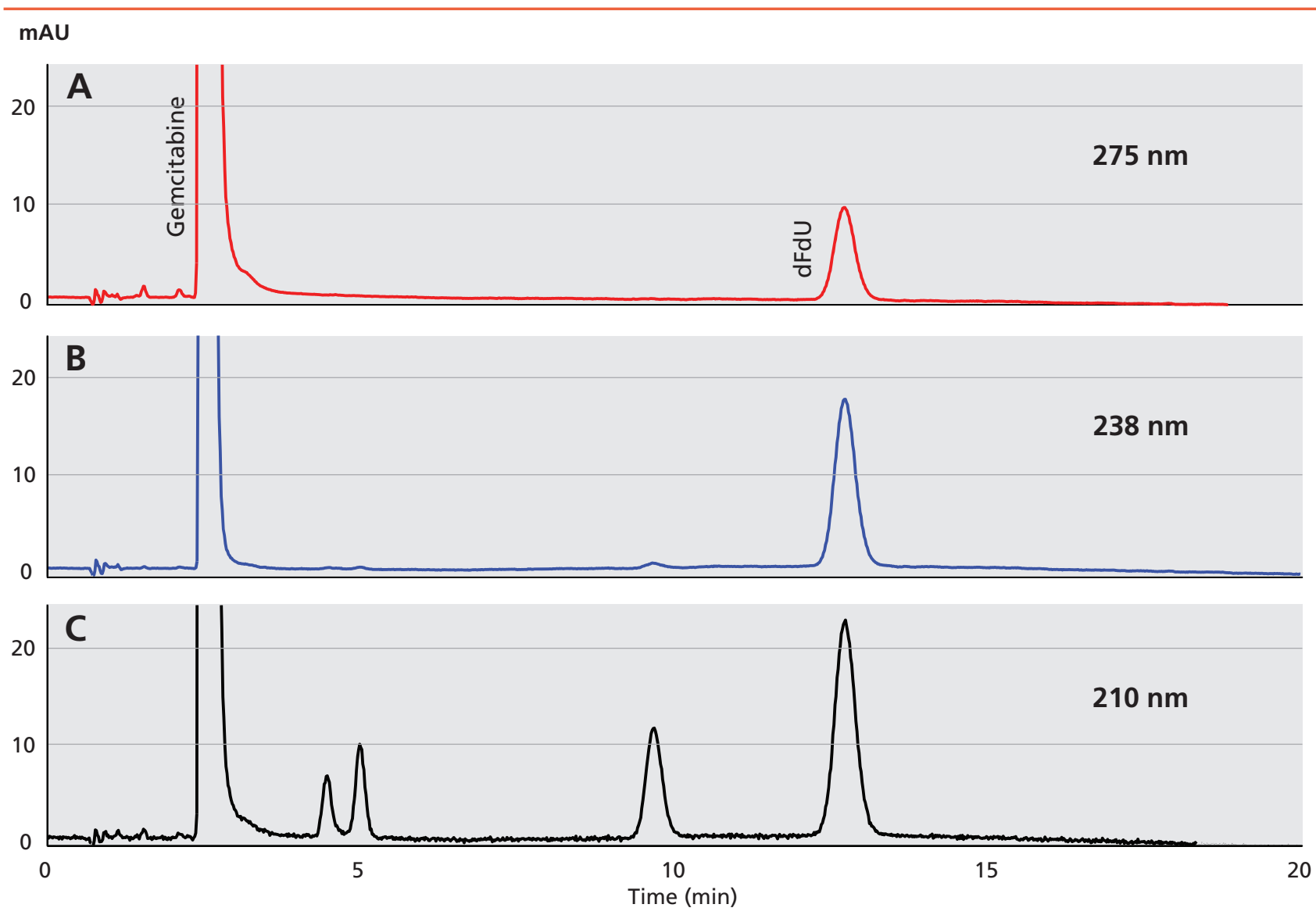

Figure 3. Ultraviolet chromatogram of gemcitabine and its impurities at different detection wavelengths. (A) At $275 \mathrm{~nm}$, the wavelength described by the European Pharmacopoeia, ${ }^{12}$ one impurity peak was detected at 12.8 minutes $(\mathrm{min})$, belonging to the main degradation product $2^{\prime}$-deoxy$2^{\prime}, 2^{\prime}$-difluorouridine (dFdU). (B) At $238 \mathrm{~nm}$, the dFdU peak is detected at even higher intensity compared with (A). (C) At $210 \mathrm{~nm}$, the wavelength used by Jansen et al, ${ }^{14}$ apart from the $\mathrm{dFdU}, 3$ other impurity peaks are visible $\mathrm{O}^{6}, 5^{\prime}$-cyclo-5,6-dihydro-2'-deoxy-2', $2^{\prime}$-difluorouridine (at 9.8 min) and diastereomeric alcohols $\mathrm{C}_{9} \mathrm{H}_{12} \mathrm{~N}_{2} \mathrm{O}_{6} \mathrm{~F}_{2}$ (at 4.4 and 5 min).

$x$-axis: retention time (min); $y$-axis: milli absorbance units (mAU)

3B). At $210 \mathrm{~nm}$, there were 4 degradation peaks: at 4.4, 5.0, 9.8, and 12.8 minutes (Figure 3C). The UV spectra and molecular masses of these peaks were compared and the impurities identified as 2'-deoxy2',2'-difluorouridine (dFdU) (at $12.8 \mathrm{~min}$ ), $\mathrm{O}^{6}, 5^{\prime}$ cyclo-5,6-dihydro-2'-deoxy-2',2'-difluorouridine (at $9.8 \mathrm{~min}$ ), and diastereomeric alcohols $\mathrm{C}_{9} \mathrm{H}_{12} \mathrm{~N}_{2} \mathrm{O}_{6} \mathrm{~F}_{2}$ (at 4.4 and $5 \mathrm{~min}$ ), as described by Jansen et al. ${ }^{14} \mathrm{Of}$ these, dFdU alone, the main inactive extracellular degradation product of gemcitabine, was described in the literature. ${ }^{19,20}$ The absence of additional peaks at all wavelengths confirmed that no products leaching from the container wall were detected. ${ }^{21,22}$

Quantitative analysis of impurities performed at $275 \mathrm{~nm}$ showed that the concentration of $\mathrm{dFdU}$ exceeded the Ph. Eur. threshold (Ph. Eur. impurity allowance: AUC impurity peak $\leq 0.10 \%$ of AUC gemcitabine peak) immediately after preparation (Table 4 ; in all $>0.1 \%$ ) .

Quantitative Analysis: Results of the quantitative gemcitabine analysis are shown in Table 5. The average active drug content of the gemcitabine bags, with and without the administration set, at all concentrations and sampling time points was $\geq 95 \%$ of the initial concentration (SD, <1\%) (Table 5).

\section{Discussion}

Over the past 10 years, dose banding has widely been integrated into clinical practice in the United King$\mathrm{dom}^{3,9,23}$ but is yet to be implemented elsewhere. ${ }^{24-26}$ This interdisciplinary project aimed to investigate its feasibility, efficacy, and practicability within the University Medical Center Freiburg. Detailed evaluation of microbiological and physicochemical 
An Analytical Approach to Dose Banding

\begin{tabular}{|c|c|c|c|c|c|c|}
\hline \multirow[b]{3}{*}{$\begin{array}{l}\text { Storage Time of } \\
\text { Sample Products }\end{array}$} & \multicolumn{6}{|c|}{$\begin{array}{l}\text { dFdU Content Quoted as \% of Gemcitabine AUC } \\
\text { (Ph. Eur. limit: } \leq 0.10 \% \text { of Gemcitabine AUC) }\end{array}$} \\
\hline & \multicolumn{2}{|c|}{$4 \mathrm{mg} / \mathrm{mL}$ Gemcitabine } & \multicolumn{2}{|c|}{$5.95 \mathrm{mg} / \mathrm{mL}$ Gemcitabine } & \multicolumn{2}{|c|}{$8 \mathrm{mg} / \mathrm{mL}$ Gemcitabine } \\
\hline & Infusion Bag & $\begin{array}{l}\text { Infusion Bag + } \\
\text { Admin Set }\end{array}$ & Infusion Bag & $\begin{array}{l}\text { Infusion Bag + } \\
\text { Admin Set }\end{array}$ & Infusion Bag & $\begin{array}{l}\text { Infusion Bag + } \\
\text { Admin Set }\end{array}$ \\
\hline Week 0 & 0.2 & 0.2 & 0.2 & 0.2 & 0.2 & 0.2 \\
\hline Week 1.5 & 0.3 & 0.3 & 0.4 & 0.3 & 0.3 & 0.3 \\
\hline Week 3 & 0.4 & 0.4 & 0.5 & 0.5 & 0.4 & 0.5 \\
\hline Week 6 & 0.6 & 0.7 & 0.7 & 0.7 & 0.7 & 0.7 \\
\hline Week 9 & 0.8 & 0.9 & 0.9 & 0.9 & 0.9 & 0.9 \\
\hline Week 12 & 1.1 & 1.1 & 1.2 & 1.2 & 1.1 & 1.2 \\
\hline
\end{tabular}

Abbreviations: AUC, area under curve; dFdU, 2'-Deoxy-2',2'-difluorouridine; Ph. Eur., European Pharmacopoeia; Infusion bag + admin set: infusion bag with intravenous administration set attached.

stability of locally manufactured dose-banded chemotherapy products has not yet been published. Considering ordering frequency and prescribing practice, several chemotherapy products proved suitable for dose banding. For the selection of carboplatin, additional practical aspects were taken into account. Because carboplatin is dosed according to renal function, the current serum creatinine should ideally be determined before therapy. After waiting for the laboratory results and dose calculation, dosebanded chemotherapy bags available off-the-shelf could represent a valuable solution to save on production time and improve patient satisfaction.

The microbiological analyses were performed using liquid medium in place of the chemotherapeutic agent, because some cytotoxic drugs have antimicrobial properties. This facilitated the distinct identification of potential microbiological contamination in line with the usual "Media-Fill" process for qualification of production processes. ${ }^{27-29}$ Attaching the intravenous administration set to the infusion bag as part of the pharmacy sterile production process reflects the current practice at large cancer centers to reduce the risk of inadvertent cytotoxic exposure during administration. Because the connection between infusion bag and intravenous administration set may constitute a predetermined breaking point and has not been checked for microbiological integrity, a container integrity test was performed in this analysis. Demonstration of complete microbiological integrity under extreme conditions, as found in a bacteria bath, was therefore significant.

Sterility and physical and chemical stability represent the basic requirements to support the implementation of dose banding in clinical practice. As expected, a few particles were noted in the

\begin{tabular}{|c|c|c|c|c|c|c|}
\hline \multirow[b]{3}{*}{$\begin{array}{l}\text { Storage Time of } \\
\text { Sample Products }\end{array}$} & \multicolumn{6}{|c|}{ Gemcitabine Content } \\
\hline & \multicolumn{2}{|c|}{$4 \mathrm{mg} / \mathrm{mL}$ Gemcitabine } & \multicolumn{2}{|c|}{$5.95 \mathrm{mg} / \mathrm{mL}$ Gemcitabine } & \multicolumn{2}{|c|}{$8 \mathrm{mg} / \mathrm{mL}$ Gemcitabine } \\
\hline & Infusion Bag & $\begin{array}{l}\text { Infusion Bag + } \\
\text { Admin Set }\end{array}$ & Infusion Bag & $\begin{array}{c}\text { Infusion Bag + } \\
\text { Admin Set }\end{array}$ & Infusion Bag & $\begin{array}{c}\text { Infusion Bag + } \\
\text { Admin Set }\end{array}$ \\
\hline Week 0 & $100 \%$ & $100 \%$ & $100 \%$ & $100 \%$ & $100 \%$ & $100 \%$ \\
\hline Week 3 & $100 \%$ & $99 \%$ & $98 \%$ & $100 \%$ & $99 \%$ & $99 \%$ \\
\hline Week 6 & $98 \%$ & $99 \%$ & $98 \%$ & $98 \%$ & $98 \%$ & $98 \%$ \\
\hline Week 9 & $97 \%$ & $97 \%$ & $96 \%$ & $96 \%$ & $96 \%$ & $96 \%$ \\
\hline Week 12 & $97 \%$ & $95 \%$ & $95 \%$ & $96 \%$ & $95 \%$ & $95 \%$ \\
\hline
\end{tabular}

Accepted stability limit ${ }^{15}: \geq 95 \%$ gemcitabine.

Abbreviation: infusion bag + admin set: infusion bag with intravenous administration set attached. 
Reinhardt et al

carboplatin infusion bags. This known phenomenon led to a recommendation by the Federal Institute for Drugs and Medical Devices (BfArM) in 2012 to filter carboplatin-containing drugs with a $0.2-\mathrm{mcm}$ filter during administration. ${ }^{18}$ The $\mathrm{pH}$ of carboplatin infusions fluctuated by $>0.3$ within samples of the same concentration. However, the relatively small $\mathrm{pH}$ differences $(\leq 0.21)$ over the full storage period were considered irrelevant because the rate of hydrolysis of carboplatin is similar between $\mathrm{pH} 4$ and 7 and a $\mathrm{pH}$ range of 3.5 to 6.5 is permitted for infusions prepared in $5 \%$ glucose. ${ }^{30}$

A subsequent purity analysis proved challenging. The $\mathrm{Ph}$. Eur. recommendations on impurity thresholds at specified HPLC wavelengths apply only to the analysis of pure gemcitabine and its impurities in the form of byproducts from the production process. ${ }^{12}$ As a solution for infusion, the expected impurities in our compounded gemcitabine infusions are hydrolytic degradation products and may additionally include leachables from the infusion bag. ${ }^{22}$ These impurities may escape detection if analysis is limited to the UV wavelength stated in the Ph. Eur. For infusion products, there is no official standard of wavelengths to determine the presence of impurities or the predicted degradation products. However, a literature review did provide guidance; the article by Jansen et $\mathrm{al}^{14}$ was most valuable for identifying these impurities.

Impurity thresholds based on the maximum daily dose of active ingredient in new drug products are identified in the International Council for Harmonisation of Technical Requirements for Pharmaceuticals for Human Use (ICH) guidelines, but their practical value is limited.$^{31}$ In order to determine the absolute content of impurities postulated by ICH, the respective reference substances are required. However, these are not generally available and the pharmacologic properties of the impurities are unknown, which constitutes a considerable challenge. Because the first industrial dose-banding products are currently entering the European market, these remaining questions should be addressed by subsequent analyses and guidelines.
The quantitative analysis of compounded gemcitabine infusions showed that, on average, $\geq 95 \%$ of active drug remained after 12 weeks storage. This is consistent with accepted pharmaceutical practice of the active drug content being $\geq 90 \%$ at time of administration. ${ }^{16,17}$ The standard agreed upon at the European Consensus Conference of an active agent threshold for cytotoxic drugs of $95 \%{ }^{15}$ was also met up to the maximum 12 weeks' storage time. These data support the preproduction and subsequent storage of infusion bags of the commonly used banded doses of gemcitabine.

\section{Conclusions}

Dose banding constitutes an innovative and efficient chemotherapy dosing and supply concept for large cancer centers. Service improvement without compromising the quality of patient care is an obvious advantage of dose banding. Detailed retrospective analysis of local prescribing practice identified several chemotherapy substances with potential for dose banding. This study demonstrated the microbiological stability of bolus syringes and infusion products, with and without intravenous administration sets, and the quantitative stability of gemcitabine products during 12 weeks' storage. This analysis also addressed key aspects in purity analysis for stored parenteral cytotoxic drug products. Further work is required to develop guidance on purity analysis and impurity thresholds, because we consider these analyses to be of unique importance in making the use of dose banding in clinical practice even safer.

\section{Acknowledgments}

The authors would like to thank Louise Wilson in Portsmouth and Dr. Tina Wardecki in Freiburg for proficient proofreading of the manuscript. They are also indebted to Brendan O'Sullivan in Cambridge and Dr. Barbara Groß in Munich, for valuable suggestions, and to Dr. Patrique Wolfrum for IT support.

\section{References}

1. Neue Daten zu Krebs in Deutschland: Pressemitteilung des Robert KochInstituts. Robert Koch Institute Web site. Available at: http://www.rki. de/DE/Content/Service/Presse/Pressemitteilungen/2015/11_2015.html. Accessed July 13, 2016.
2. National Health Service (NHS) England. Chemo drug optimisation to improve patient experience of cancer treatment. NHS England Web site. Available at: https://www.england.nhs.uk/2016/05/chemo-drugoptimisation/. Accessed July 20, 2016. 
An Analytical Approach to Dose Banding

3. Kaestner S, Sewell G. Pharmacoeconomic aspects of dose-banding. Hospital Pharmacy Europe Web site. Available at: http://www. hospitalpharmacyeurope.com/featured-articles/pharmacoeconomicaspects-dose-banding. Accessed April 7, 2015.

4. Plumridge RJ, Sewell GJ. Dose-banding of cytotoxic drugs: a new concept in cancer chemotherapy. Am J Health Syst Pharm 2001;58:1760-1764.

5. Pouliquen AL, Escalup L, Jourdan N, et al. Dose standardisation of anticancer drugs. Int J Clin Pharm 2011;33:221-228.

6. Chatelut E, White-Koning ML, Mathijssen RH, et al. Dose banding as an alternative to body surface area-based dosing of chemotherapeutic agents. Br J Cancer 2012;107:1100-1106.

7. Zavery B, Marsh G. Could logarithmic dosing change the way cytotoxics are prescribed? Clin Pharm 2011;3:116-118.

8. Zavery B, Burnett B, Oldcorne M. Vision paper on the future of pharmacy technical services and provision of patient specific parenteral chemotherapy treatments. EJHP Pract 2011;17:57-64.

9. Ward C. Dose-banded and outsourced IV chemotherapy-a strategy to balance demand and capacity. Clin Pharm 2013;5:29-31.

10. Thiesen J, Krämer I. Stabil-Liste: physikalisch-chemische Stabilität, Kompatibilität und Inkompatibilität parenteral applizierbarer Zytostatika, Virustatika und Supportivtherapeutika, 6th edition. Berlin, Germany: ADKA, Bundes-verband Deutscher Krankenhausapotheker; 2013 [in German].

11. Vigneron J, Demoré B, Monfort P, Gindre I. Stabilis 4.0. 2015. Available at: http://www.stabilis.org/. Accessed February 12, 2015.

12. Council of Europe. European Pharmacopoeia. Strasbourg, France: Council of Europe; 2010

13. Pharmaceutical Inspection Convention/Pharmaceutical Inspection Co-Operation Scheme. Recommendation on the Validation of Aseptic Processes. Available at: http://www.picscheme.org. Accessed July 25, 2016.

14. Jansen PJ, Akers MJ, Amos RM, et al. The degradation of the antitumor agent gemcitabine hydrochloride in an acidic aqueous solution at $\mathrm{pH} 3.2$ and identification of degradation products. J Pharm Sci 2000;89:885-891.

15. Bardin C, Astier A, Vulto A, et al. Guidelines for the practical stability studies of anticancer drugs: a European consensus conference. Eur J Hosp Pharm 2012;19:278-285.

16. Schwendinger J, Schaaf D, Marschall-Kunz B, Walz-Schreiber B. Haltbarkeits- und Herstellungsdaten deutscher Arzneimittel. Stuttgart, Germany: Deutscher Apotheker Verlag; 1998 [in German].

17. Swissmedic. Pharmacopoea Helvetica, 11th ed. Bern, Switzerland: Swissmedic; 2012.
18. Carboplatin: Empfehlung zur Filterung von bestimmter Carboplatinhaltigen Arzneimitteln mit 0,2um-Filtern. Available at: https://www. bfarm.de/SharedDocs/Risikoinformationen/Pharmakovigilanz/DE/ RI/2012/RI-carboplatin3.html. Accessed July 25, 2016.

19. Mini E, Nobili S, Caciagli B, et al. Cellular pharmacology of gemcitabine. Ann Oncol 2006;17(Suppl 5):v7-v12.

20. Abbruzzese JL, Grunewald R, Weeks EA, et al. A phase I clinical, plasma, and cellular pharmacology study of gemcitabine. J Clin Oncol 1991;9:491498.

21. Jenke D, Poss M, Story J, et al. Development and validation of chromatographic methods for the identification and quantitation of organic compounds leached from a laminated polyolefin material. J Chromatogr Sci 2004;42:388-395.

22. Larsson I, Trittler R, Navas Iglesias N. Leachable/extractable issues in a pharmacy setting. Available at: http://www.hospitalpharmacyeurope.com/ cytotoxic-agents/leachableextractable-issues-pharmacy-setting. Accessed October 10, 2016.

23. Robb D. A day in the life of ... an oncology pharmacist. Available at: http:// www.hospitalpharmacyeurope.com/featured-articles/day-life-oncologypharmacist. Accessed February 2, 2013.

24. Guinto JB, Szabatura AH. A perspective on dose banding. J Natl Compr Canc Netw 2013;11:357-359.

25. Dose banding: a way to rationalize the production of chemotherapy Available at http://www.stabilis.org/sourcesPDF/Fichier.10868.3.pdf. Accessed August 1, 2016

26. Pérez Huertas P, Cueto Sola M, Escobar Cava P, et al. Applying dose banding to the production of antineoplastic drugs: a narrative review of the literature. Farm Hosp 2015;39:210-216.

27. Paris I, Paci A, Rey JB, Bourget P. Microbial growth tests in anti-neoplastic injectable solutions. J Oncol Pharm Pract 2005;11:7-12.

28. Jordheim LP, Ben Larbi S, Fendrich $O$, et al. Gemcitabine is active against clinical multiresistant Staphylococcus aureus strains and is synergistic with gentamicin. Int J Antimicrob Agents 2012;39:444-447.

29. Krämer I. Viability of microorganisms in novel antineoplastic and antiviral drug solutions. J Oncol Pharm Pract 1998;4:32-37.

30. Kaestner S, Sewell G. A sequential temperature cycling study for the investigation of carboplatin infusion stability to facilitate "dose-banding." J Oncol Pharm Pract 2007;13:119-126.

31. Guidance for Industry: Q3B(R2) Impurities in New Drug Products. Available at: http://www.ich.org/products/guidelines/quality/article/ quality-guidelines.html. Accessed July 25, 2016. 